\title{
Chapter 7 \\ Conflicted Reproductive Governance: \\ The Co-existence of Rights-Based \\ Approaches and Coercion in India's \\ Family Planning Policies
}

\author{
Maya Unnithan
}

\section{Introduction}

The late 1990s saw a shift in the implementation of Indian health and population policies from a focus on fertility control in its Family Planning programme towards a rights-based and choice- and participation-oriented Reproductive Health approach. On the ground, in everyday contexts of service provision, this meant an abolition of 'targets' (numbers of women to be sterilised monthly and annually) set by the state for community health workers. On the face of it, the adoption of a 'target-free approach' relaxed state surveillance of poor pregnant women and released health workers from the burden of achieving a set number of cases over a specified period, a regulatory mechanism through which they were held to account (Ramasubban \& Jejheebhoy, 2000; Visaria, 2000). Instead of actively pursuing tubectomy cases, staff at health centres and sub-centres were to focus instead on the provision of a choice of contraceptive options, offering reversible methods (condoms, pills, intrauterine devices) alongside sterilisation. Popularly known in health policy parlance as the 'cafeteria approach' to contraception (GOI, 2007), the practice came to symbolise the significant shift from a population to a people-centred policy approach to maternal and reproductive health.

In this chapter I examine the processes, contradictions and outcomes that accompanied such a critical and important shift in population policy and what this reveals about the dynamics of reproductive governance in India. I build on the concept of reproductive governance as the 'subject making powers of moral regimes directed towards reproductive behaviours and practices' (Morgan \& Roberts, 2012, p. 244) in the context of the Indian state's long embrace of rights-based, empowerment approaches in its development practice. Drawing on ethnographic work on maternal

\author{
M. Unnithan $(\bowtie)$ \\ Department of Anthropology, University of Sussex, Sussex, UK \\ e-mail: M.unnithan@sussex.ac.uk
}


and reproductive health in the state of Rajasthan in Northwest India from 1998 to the present, and more recently with policy makers, health professionals and NGOs, I suggest that the discourse of rights in the area of maternal and reproductive health speaks more to processes of State empowerment than to enhancing reproductive autonomy among claimants on-the-ground. Participatory forms of policymaking and rights discourse have instead helped to transform the State itself into an 'activist' institution in terms of its modus operandi and rights advocacy work (Biehl, 2004; Unnithan, 2019; Unnithan \& Heitmeyer, 2014). ${ }^{1}$

The main policy focus in the chapter is India's axiomatic National Population Policy (NPP) of 2000 (GOI, 2000), which is examined alongside a set of reproductive and child health policies in India (RCH-I and RCH-II) implemented between 1997 and 2005, and the policy of Safe Motherhood (Janani Suraksha) actioned under the National Rural Heath Mission (NRHM) of 2005. Drawing on intersectional, feminist and Foucauldian analysis in the domain of population governance (Greenhalgh, 2005; Morgan \& Roberts, 2012; Ram, 2001; Das, 2015; De Zordo, 2012; Dean, 2001; Gupta, 2001), I suggest that the simultaneous promotion of two conflicting approaches to governance within the same NPP policy may stem from a broader dilemma that faces modern states 'doing' development (Hanson \& Stepputat, 2001). It may also stem from a more particular concern of well-being and reproductive choice in policymaking at the end of the second millennium in India.

Policy in an anthropological sense is regarded as a field that is constituted by performative social practices of regulation which are both created by and 'create particular social and cultural worlds' (Shore et al., 2011). These have a 'domaining effect' and are agentive in that they shift action (Wright, 2011, p. 27). I also regard policy through an affective lens and a Critical Medical Anthropology (or CMA) approach to health policy. Such an approach regards policy formation and enforcement 'as reflecting simultaneously the compromise between, as well as the balancing of power among, conflicted forces (social groups with different and opposed interests)' (Singer \& Castro, 2004, p. xiv).

Policymaking as a contextual practice is developed in the chapter through the policy perspectives of community health workers, health professionals (doctors, clinicians, public health specialists) and policy makers (bureaucrats, prominent civil society actors, lawyers and politicians). Policy guidelines and programme reports have enabled analysis of the embedded hierarchies and power at play in practices of health governance. Analysis of these documents reveals a return to previous coercive (in terms of restricted choice) family planning policies, even as the language of human rights frames the overall approach. The only difference is that the language of coercion is more implicit and less overt than in the previous family planning policies of the 1970s, a pre-rights-based policy era. I use the term 'coercive' to mean 'choice restrictive' in the sense that policies which may or may not intend to be coercive are those where, in practice, choice is restricted (also see Brunson, 2019;

\footnotetext{
${ }^{1}$ I use the word 'state' to denote regional states in India, and the term 'State' to mean the central authority ruling a sovereign territory.
} 
Senderowicz, 2019). I also suggest that contraceptive coercion, as Senderowicz argues, 'sits on a spectrum and need not involve overt force or violence but can also result from more quotidian limits to free, full and informed choice' (2019, p. 1).

Despite current, ostensible state withdrawal from an explicit promotion of sterilisation (especially tubectomies for women), it is a practice that is promoted on the ground with some poorer women and couples who have met their childbearing aspirations continuing to use the method. However, I argue that the reasons for this uptake are very different from those which policy makers envision. Examining the factors underlying the local reproductive behaviour that shapes health worker practices as well as some women's preference for tubectomies provides key insight into the exercise of reproductive choice as simultaneously supporting and resisting government control. These observations lead me to suggest that the substitution of an existing bio-politics of population control with a bio-politics of the 'self', aimed at enhancing individual choice and personal autonomy (de Zordo, 2012) is not as clear-cut as imagined by policy makers in India (Unnithan, 2019).

\section{A Note on Methods}

The chapter is an outcome of discussions and reflection on several previous periods of ethnographic work. During the first period (1998-1999), I gathered data on the reproductive journeys of over 50 members of a peri-urban Muslim community and urban basti dwellers in Jaipur city, with a further focus on emotion and agency in contraceptive practices and recourse to sterilisation (2000-2006). Between 2009 and 2012, I participated in collaborative research with members of 34 civil society groups in Rajasthan. This included consultation with over 55 individuals from a range of policy-engaged civil society organisations (henceforth CSO) members and state and regional health and family planning policy members working on promoting (and challenging) rights-based maternal and reproductive health policies (Unnithan et al., 2010). During a further period of fieldwork in 2015 and with local field assistance, I conducted semi-structured interviews and life-histories with 12 newly formed Accredited Social Health Activist (ASHA) health workers in Jaipur district. The chapter also draws on my analysis of national and regional health and family welfare policy documents (GOI, 2000, 2006, 2007). Recent informal discussion (2017-2019) with members of civil liberty, legal professional and rights-based organisations as well as university academics has also informed the ideas in this chapter.

In the next section, I elaborate on the conceptual approaches which underpin the observations made in this chapter. The section following that explains the policy rationale underlying the simultaneous roll out of conflicting reproductive objectives within the latest Indian family planning policy. The final sections explore the effects of these policies in-situ through the work of local health workers and the conflicted governance practices of the Indian State. 


\section{The Anthropology of the State and Reproductive Governance}

Anthropological analysis of the cultural processes through which the state is 'instantiated' and experienced has shown how it is an entity which is less coherent and more fragmentary than imagined (Sharma \& Gupta, 2006, p. 11). With the increasing pervasiveness of rights-based advocacy in global health, CSO members who have established expertise of operationalising rights-based ideas and language in their maternal and reproductive health programmes have become increasingly valued in national level policy working groups. This has led to the co-construction of the rights-based parts of State policy documents by policy makers, bureaucrats and members of leading CSOs.

Conceptualising the state as a 'dispersed ensemble of institutional practices and techniques of governance' (Hanson \& Stepputat, 2001, p. 14) and governmentality as 'beyond the state' (Foucault, 1998; Dean, 2001; Gupta, 2001), offers two profound insights when applied to the processes of reproductive health policymaking in India. First, it suggests the potential for multiple practices of State policymaking to co-exist, and second, to realise that the co-creation of policy occurs across different state and non-state actors. Hanson and Stepputat (2001) trace the simultaneous execution of competing policies to the increasingly challenging conditions under which modern states function: where their authority is constantly being called into question through global markets, separatist movements and ethnic conflicts, on the one hand, but equally where the state is being framed as indispensable to global efforts, for instance, to deliver development programmes effectively or promote a human rights culture and through which new modalities of governance emerge. As I argue later, this is clearly the case in India's population policy, which is situated between two conflicting discourses of population management: The first is governed by a demographic rationale that advocates strict State regulation of fertility. The second has a rights-based rationale that promotes individual reproductive choice and bodily autonomy. The Indian population policy is at the same time a technique of reproductive governance, which Morgan and Roberts regard as:

...the mechanisms through which different historical configurations of actors - such as state, religious, and international financial institutions, NGOs, and social movements - use legislative controls, economic inducements, moral injunctions, direct coercion, and ethical incitements to produce, monitor, and control reproductive behaviours and population practices (2012, p. 241).

Anthropological scholarship on reproduction, in addition, provides critical understanding of family planning policies as part of broader processes, especially those concerned with State projects of modernity and citizen-making. It is useful to delineate three kinds of narratives and related concepts that emerge within this approach which are resonant with policymaking around family planning in India. First, a dominant narrative identified in anthropological studies of family planning policymaking in high population, 'developing' country contexts is about 'becoming modern' and achieving economic growth through curtailing demographic expansion (a rationale driven by the classic demographic transition theory; Greenhalgh, 1995). 
Anti-natal State population policies in India and China, for example, are primarily framed through a narrative of progress whereby modern citizens are produced (Greenhalgh, 2005; Chen, 2011; Anagost, 1995; Van Hollen, 2003; Ram, 2001). Such policies work by attributing value to specific kinds of populations (rural, poor and so on) whose members become subjects to be modernised. They also objectify women by defining them primarily through their reproduction (Ram, 2001; Brunson, 2016). However, individuals within specific social groups/classes, including women community health workers such as the ASHA (Accredited Social Health Activist) described in this chapter, differ in the extent to which they partake in such projects deemed to be of national importance (also Anagost, 1995; Kanaaneh, 2002; Mishra, 2014). People do not necessarily follow state directives or take up family planning incentives without paying heed to their own agendas for social reproduction (Kanaaneh, 2002; Varley, 2012).

A second important narrative in anthropological work on family planning is of the pervasiveness of neoliberalism and market economics within health policy discourse. This economic thinking in public health policy is reflected best in India in the embrace of privatisation as an effective mechanism in the delivery of public health care (Qadeer \& Viswanathan, 2004; Roalkvam, 2014, among others). Private services may often be popular precisely because they are presented as caring not coercive (Chen, 2011). Indian population policies, as Qadeer and Viswanathan (2004) argue, have supported the privatisation of public health care guided by the principle that private care is more cost-effective, efficient and of better quality compared to public services. Policymakers consider state provision of monetary incentives and linked penalties (such as the exclusion from standing from political office) linked to contraceptive uptake as an effective means to regulate family size (the 'small family norm'; Das \& Uppal, 2012).

A third perspective in the anthropological literature on family planning is that of morality, affect and the role that emotions such as desire and fear play in the internalisation (in a Foucauldian sense) of the missives of family planning programmes, both by the health workers tasked with implementing the policies and those targeted by them. More broadly, these perspectives speak to (a lack of) power and notions of stratified reproduction - where the fertility of some individuals and classes is more highly valued than others (Ginsburg \& Rapp, 1995; Unnithan, 2019).

Next, I analyse how each of these perspectives is also critical to framing Indian family planning policies before returning to examine their embodiment within health-worker practices.

\section{India's Family Planning and Underlying Policy Rationale}

India is hailed in global health policy and planning circles as the first country to have instituted a family planning programme in 1952 and has several policy documents and draft policy statements setting out its population programmes, especially between 1976 and 2000. The Indian National Population Policy (NPP) 2000 (GOI, 
2000), the final and most comprehensive policy to date, is a landmark document which is connected to policy thinking about family planning. Here, I examine the policy framework approved by parliament in 1999, developed over the previous decade alongside critiques of earlier reproductive health programmes and policies in the run up to the International Conference on Population and Development in Cairo in 1994, and its projection forward into the rights-based policies of the National Health Mission in 2005.

The Indian National Population Policy (NPP) 2000 provides a policy framework for advancing the goals and strategies from 2000 to 2010 (and now till 2026) suggesting that family planning be carried out to the 'extent necessary' for reducing birth rates to stabilise population at a level consistent with the requirement of the national economy and replacement levels of the 'Total Fertility Rate' or 'TFR' (GOI, 2000, p. 2; emphasis added). ${ }^{2}$ At the same time, the NPP is distinctive from previous policy statements on family planning in its use of the language of choice and consent and the explicit removal of the aggressive pursuit of family planning 'targets'. In its opening statement, the NPP affirms the commitment of the government towards the twin goals of a 'voluntary and informed choice and consent of citizens while availing of reproductive healthcare services, and the continuation of a target-free approach in administering family planning services' (NPP 2002 ibid.; emphasis added), explicitly referring to the removal of sterilisation targets for health workers. I use the word 'target' in the specific context of sterilisation as it was referred to in policy documents and in conversations with health workers.

The policy is set out with three time-bound objectives in mind: (i) an immediate goal of addressing unmet needs for contraception ${ }^{3}$; (ii) a medium term objective of bringing the TFR down to replacement levels by 2010; and (iii) a longer term goal of stabilising population growth by 2045 at a level consistent with the requirements of sustainable economic growth, social development and environmental protection. It was deemed imperative that the small family norm be adopted by the reproductive age group 'without delay or exception' given that $45 \%$ of the population increase was due to births of over 2 children per family.

The NPP recognised three causes for the high fertility rates: first an 'unmet need for contraception' as approximately half of the population in their reproductive years were not protected; second high levels of infant mortality, which it was deemed increased the desire for having more children (referred to as 'wanted fertility'); third, the high numbers of marriages taking place under 18 years (and births with intervals of less than 24 months) was another factor which was regarded as contributing to high levels of fertility.

As it is set out, the policy demonstrates a desire to reduce population numbers in order to enhance the benefits of economic growth, but equally shows concern for the

\footnotetext{
${ }^{2}$ The Total Fertility Rate or TFR is defined in the document as the average number of children born to a woman during her lifetime.

${ }^{3}$ The 'unmet need for contraception' is a problematic metric which in the context of global health discourse often serves to exclude health subjectivities and everyday experiences (Storeng \& Béhague, 2017; Das, 2015; Unnithan, 2019).
} 
welfare (health and well-being) of the population, especially mothers and children in a context of high maternal and child mortality. The underlying family planning policy rationale in India, as in other high population, high mortality settings, is driven by the public health perspective of maternal risk. Here, risk is conceptualised as the risk to the life of the mother and accompanied by statistics which demonstrate that contraceptive use has the potential to reduce maternal deaths (also Storeng \& Béhague, 2017; Brunson, 2019). The World Health Organization (WHO), for example, suggests that in 2017, contraceptive use prevented approximately 308 million unintended pregnancies in developing countries and the need for unsafe abortion. Public health literature underscores the significance of using reversible methods in contexts where birth intervals (spacing) between children are less than 3 years as mothers and infants are more prone to a higher risk of death in this instance (WHO ibid).

Thus, pursuing a family planning policy becomes an example of a practice of 'good government' by which the State not only exercises authority over its citizens but also sees itself as fostering their health and happiness - much in the same way as Gupta notes for the anganwadi creche programmes focused on improving child nutrition (2001, p. 66). India's attention to the welfare of its population is an example of 'governmentality' (in Foucault's sense), where modes of government are not necessarily parts of state apparatus (Gupta, 2001, p. 67). It is the 'welfare' aspect, conceived as health benefits that the spacing of children confers on married women, which has provided the underlying rationale for Family Planning since the start of official health planning in the 1950s. This logic can be traced back to the concerns of the colonial state and medical establishments about high levels of maternal mortality and the health of poor Indian women who were most prone through malnutrition and anaemia to maternal complications (Arnold, 2006; Hodges, 2006). It was thought that poor women's health would improve substantially when their fertility was controlled. The provision of contraceptives would empower poor women to practice spacing and would bring them relief from constant childbearing and related physical exhaustion.

Ideas about 'fertility control as beneficial to women's health' emerge within the colonial period and take hold within the closing years of the British rule as set out by the Bhore committee report of 1946 which was regarded as the first health 'policy' in terms of its recommendations (Government of India \& Ministry of Health and Family Welfare, n.d.). Some of this early thinking around fertility and women's health is evident in India's first family planning programmes from 1952 onwards (Jeffrey \& Jeffrey, 1997). It is, as feminists have argued, a population control approach that views women as 'potential contraceptors' or 'producers of too many babies' rather than as individuals whose health is of inherent...' value (Lane, 1994, p. 1303). The instrumentalist view of women as reproducing machines was taken to task in the deliberations on the rights approach to reproductive health at the International Conference on Population and Development at Cairo in 1994 (UNFPA, $2004,2008)$ to which India was signatory and to which the NPP policy is formulated in response. 
A key strategy outlined in India's National Planning Policy 2000 for making the State more accountable to women's welfare was a devolution away from responsibility of individual states for delivering family welfare programmes. Instead, political and health functionaries and structures at the village level (namely panchayats or village councils and sub- and primary health centres) would deliver such programmes. Decentralisation intended to 'strengthen, energise and make accountable' the first points of contact in the health system (2002, p. 7). Two further strategies were notable: (i) to collaborate with NGOs in the private sector (especially where government interventions were deemed to be insufficient) in a complementary manner, and (ii) to bring in legislation which would support the process. It was with the latter in mind that the 42nd constitutional amendment Act 1976 was enacted in 2000, freezing the number of parliamentary seats until 2026 so that state governments could 'effectively and fearlessly pursue the agenda for population stabilisation' (2002, p. 16).

The 'strategic themes' as laid out earlier in the NPP 2000 were accompanied by a set of motivational measures for the adoption of a small family norm. No similar measures are mentioned to ensure the exercise of rights-based choices. For example, village councils and their leaders were rewarded and honoured for 'exemplary performance' in universalising the small family norm. Poorer couples, who were the focus of the programme, gained health insurance and cash benefits if they had only two children and chose to go in for sterilisation (GOI, NPP, 2000). Community health workers were valorised for their motivational work in the uptake of family planning and institutional deliveries. Before we turn to explore how local ASHA health workers embodied their motivational work in the next section, it is important to track the narrative of choice and reproductive rights within family planning policymaking.

\section{Tracking Rights-Based Ideas in Family Planning}

Modern Indian health-planning history from the 1950s, as we saw earlier, begins with an emphasis on population control and contraception as urgent and invested with national importance. With the seductive notion that 'contraception was the best form of development', individual rights and choices with regard to childbearing quickly came to be regarded as secondary to the 'human rights of the nation' (public address of Congress Prime Minister Indira Gandhi on Indian's family planning programme; Dhanraj, Something like a War 2011(1991)). Following the family planning atrocities committed during her political reign, the mid to late 1980s in India became a time of popular dissent against the failure of the state more broadly, but also against the failure to meet women's reproductive rights and related health needs. Activists and feminist organisations particularly highlighted the malpractices and unethical conduct of health workers, who were subjected to sterilisation targets to carry out coercive birth control strategies (Ramasubban \& Jejheebhoy, 2000; Visaria, 2000). The critiques of India's family planning programme by women's organisations, health activists and feminist scholars (see, for example, Visaria, 
2000; Ramasubban \& Jejheebhoy, 2000; Ram, 2001; Rao, 1999; Chatterjee \& Riley, 2001; Qadeer \& Vishwanathan, 2004) subsequently drove the policy focus on reproductive rights and women's health at the Cairo conference on Population and Development.

In its rights-based language and target-free approach, the NPP was very much influenced by the Reproductive Health approach adopted at the International Conference on Population and Development (ICPD) held in Cairo in 1994, to which India was a signatory. Population stabilisation as agreed at ICPD 1994 could be met naturally and not as a matter of control or coercion if people's needs for family planning and reproductive health services along with basic health and education needs were met (Muttreja, 2019). Post-Cairo, India ostensibly adopted a rights-based approach in its Indian health policy documents, and a 'target-free' approach in its family planning programme. However, we find a continued emphasis in the NPP and in the new Reproductive and Child Health $(\mathrm{RCH})$ programmes described later on the pursuit of aggressive family planning methods of irreversible means of contraception (sterilisation) rather than a choice of reversible forms of contraception (pills, condoms, IUD). The state, as scholar-activists note, preferred to mobilise targets to enforce reproductive control (Rao, 1999; Visaria, 2000) and to practice coercive population control even as it supported a policy of reproductive health rights. The fact that international aid was tied to demographic performance and the uptake of contraceptives was identified by these activists as a key factor in shaping the approach of the Indian state (Rao, 1999; Qadeer \& Vishwanathan, 2004).

Between 1997 and 2003 in a post-Cairo reproductive health context, the Ministry of Health and Family Welfare (MoHFW) launched its new RCH-I programme in which a comprehensive and integrated reproductive service approach was devised to act as a corrective to the overly family planning (i.e., contraception-orientated) character of primary healthcare services. A new Reproductive Health approach was set out as being about a decentralised, comprehensive, non-vertical, integrated focus on the 'quality of care' and in which there would be no family planning 'targets' (cases of sterilisations) set for health workers at the primary and sub-centre levels such as the Auxiliary Nurse Midwife (ANM).

However, on-the-ground ANMs were expected to continue to push family planning in their work above all else. This was further reflected in the $\mathrm{RCH}$ policy documents discussed next. In 1998, the role of the ANM became limited to family planning, immunisation and 'superficial healthcare' (Mavlankar et al., 2010).

When the Reproductive and Child Health $(\mathrm{RCH})$ programmes, RCHI (1997-2002) and RCH II (2003-2005) (programmes which predated the National Rural Health programmes of 2005) were rolled out, it was stated that their 'strategic orientation' was to be consistent with the Millennium Development Goals, the National Population Policy (2000-2010), the tenth five-year plan (2002-2007), the National Health Policy 2002 and the Vision 2020 document. The programmes would therefore promote a combined focus on reducing the maternal mortality ratio, the infant mortality rate and the total fertility rate. At the same time, the programmes would promote 'couple protection' (term used for contraceptive uptake) through the provision of a range of contraceptive options from condoms and intrauterine devices 
(IUDs) to the pill. The RCH documents referred to the provision of this range of contraceptives as the 'cafeteria approach' to family planning and were set out as offering reproductive choice to women and couples.

\section{The Policy Rationale for a Return to Sterilisation}

According to principle 6 of the RCH II planning document: 'the programme would include voluntary and informed choices in administering family planning services (there will be) clear tasks for service providers to provide quality services to meet unmet needs of family planning and spacing methods in desirable quantities' (my emphasis). The word 'right' appears in 3 of the 9 RCH II programme principles: principle 3: the poorest have the right (my emphasis) to get full value for the money being spent by the government or by themselves; principle 5: female children have an equal right to health, emergency medical aid and to live with human dignity and in principle 6: promoting contraceptive choice, as alluded to earlier. The same paragraph continues to state an overriding concern with population growth especially in the 'lagging' states (referring to the poor economic growth in the five states of Bihar, Madhya Pradesh, Odisha, Rajasthan and Uttar Pradesh), where it was estimated it would take over 26 years to achieve the replacement level fertility rate of 2.1. In these economically 'lagging' states, financial incentives (referred to as 'compensation') were to be provided to clients (term used in the document) to enhance contraceptive uptake. Cash incentives were provided to encourage uptake of contraceptive services. These ranged from approximately INR 600/- for tubectomies and INR 650/- for vasectomies, with a heftier sum of INR 5000/- including access to medical termination services offered in case of failures.

There are thus clear policy measures to return to state-promoted sterilisation (and the preference for an irreversible form of contraception) in Rajasthan despite the contraceptive choice espoused in national policy documents. In this sense, the RCH II plan, like the National Population Plan, reaffirmed the State's commitment to 'promote vigorously the small family norm to achieve replacement levels of TFR' (GOI MoHFW, 2000). The continued focus on sterilisation which Das and Uppal (2012) suggest demonstrates not just a continuing anxiety of the state around 'population explosion' but more fundamentally a lack of understanding of the actual dynamics of population growth. India has an increasingly 'young' population which they emphasise requires provision of spacing rather than the terminal methods of contraception entailed in sterilisation. The predominance of sterilisation as a method provided by the State ironically leads to a greater spurt in population growth, precisely because younger couples rush to complete their families (ibid.).

Other, neoliberal forms of argument were also mustered in the policy document to legitimise the case for a return to sterilisation. An argument that gained currency in Indian health policy circles was that female sterilisation or tubal ligation (and as described in the health planning documents) was both a popular and cost-effective choice with little surgical time involved, as requiring inexpensive equipment 
especially with the recent mini laparotomy (key hole sterilisation) method employed. As the client could be discharged $2-4 \mathrm{~h}$ after the surgery and without need for postoperative hospital-based care, it placed a minimum burden on institutional resources (Unnithan, 2019). The popularity of this method among planners was backed by statistics showing that sterilisation was the preferred option for $34 \%$ of currently married women (in 1998-99). ${ }^{4}$ Accordingly, it was argued that sterilisation procedures were to be made available and provision was to be expanded in the future from the existing programme into 2005-2010 to all the community health centres and primary health centres in the country (and not just the five 'lagging' states). Each location would be provided additional funds for an operating theatre and to hire a medical officer trained in sterilisation. The government set up incentive packages to attract clinics in the private sector to provide family planning services especially sterilisation (promising fixed payments for clients served by the private facility as well as access to public facilities on a fee sharing basis (RCH II planning document)).

From a close reading of the state planning documents, I suggest that the continued emphasis on sterilisation signals a deeper neoliberal rationale in operation. As most other contraceptive methods are resource intensive and expensive to provide, policy makers do not regard them as cost-effective. For instance, the copper T intrauterine device requires administering and counselling by a trained paramedic.

It also requires monitoring over the period of its use. Sterilisation by comparison requires 'little surgical time, involves minimal discomfort and the client is discharged 2-4 hours after surgery' (GOI, 2007, p. 87). The use of reversible methods (IUDs, condoms and pills) is also regarded as a 'riskier' (including cost-wise) option for the state than sterilisation as it entails the possibility that women could 'change their minds' and discontinue use which would be difficult and expensive to monitor (RCH PIP ibid). As a result, the very contraceptive methods which provided women with the most choice were also those regarded as most 'unreliable' by health planners. As a result, even though the planning documents espoused a 'cafeteria' approach to contraceptive choice, only one method (sterilisation) was available. Even when the options of the Copper T or condoms were available at primary health centres, it was sterilisation that was continuously promoted as the most reliable method by community health workers during the post RCH policies from 2005 as evidenced during my later field research discussed in the next section.

The renewed emphasis on sterilisation targets and camps in the family planning program was accompanied by the introduction of new metrics of 'Expected Levels of Achievement' (or ELA) as Iyengar and Iyengar (2000) note, to evaluate healthworker performance. But as the authors suggest this is commonly perceived as the new phrase for 'targets' in the clinical context of Rajasthan where they work.

\footnotetext{
${ }^{4}$ The group of currently married women is not broken down by age, which I have found to be an important factor in determining whether to go in for reversible or irreversible forms of contraception.
} 


\section{Embodying Conflicted Governance: ASHA Health-Worker Perceptions and Practices}

In 2005, the Indian government launched its flagship National Rural Health Mission (NRHM), its most ambitious restructuring of health delivery systems, in line with a rights-based approach to deliver on the Millennium Development Goals (GOI, 2006). There was major financial investment in promoting safe childbirth under the NRHM and a new category of health worker, the Accredited Social Health Activist (ASHA), was created under its Janani Suraksha Yojana (JSY) or safe motherhood programme in addition to the Auxiliary Nurse Midwife (ANM). By 2015, over 300,000 ASHA had been selected and this was further advanced to approximately 825,000 women working as ASHA nationally (NHSRC, GOI, 2011).

The appointment of the ASHA health worker was in keeping with the vision of an 'integrated development' approach and the 'multi-purpose' nature of health work expected from her. The ASHA appointed were tasked with improving the health status of their communities through: (i) 'securing people's access to health services; (ii) improving health practices and behaviours; and (iii) providing essential and feasible healthcare provision' (GOI \& NHSRC, 2011). The primary work assigned to the ASHA was 'to act as a health motivator and educator for women in the villages' (referred to by the women health workers I met as motivator ka kaam, or 'motivation work') and to identify and accompany pregnant women to hospital. In terms of the role of the ASHA in the JSY safe motherhood programme, the NRHM guidelines state her to be an 'honorary volunteer' who was to 'escort' women for institutional deliveries and work closely with the Auxiliary Nurse Midwife (ANM) as her helper (NHSRC, GOI, 2011, p. 2).

In 2009, the first ASHA were appointed in Rajasthan and along with a research team I conducted interviews with both ASHA and ANM at joint meetings of the Village Health and Sanitation Committees (VHSC) led by nodal Civil Society Organisations working closely with the state (Unnithan \& Heitmeyer, 2014). A major activity which the ASHA undertook along with the Auxiliary Nurse Midwife (ANM) was to promote family planning especially the use of reversible methods of contraception (IUD, condoms and hormonal pills). Both ASHA and ANM provided contraceptives and raised awareness of their use, with the ASHA conducting home visits while the ANM remained in the health centre. Promotion of contraceptives was a component of a whole host of other activities which were part of an ASHA's everyday schedule of home visits to pregnant women and children under 5 years. ASHA activities included referral to government facilities for a pregnancy complication, sharing knowledge of best breastfeeding practices, prevention of diarrhoea, promoting immunisation for infants and undertaking sputum tests for the identification of TB. The diverse work of the ASHA was reflected in the diverse content of the bag each ASHA carried, which apart from an identity card had a drug kit filled with a range of items from ORS rehydration salts to paracetamol to contraceptives and betadine. ASHA were also expected to motivate women to give birth in stateaccredited hospital settings. 
In 2015, I interviewed 12 ASHA from nine villages in the Sanganer sub-division (tehsil) of Jaipur district. These were women who were between 23 and 45 years old and had educational qualifications ranging from eighth class pass (the minimum requirement for the job) to MA and BEd. I was told that their 'motivation work' (motivation ka kaam) involved regular visits to all the village households (typically 200 in number) and involved discussions on contraceptive use with pregnant, lactating and young mothers identified and a use of persuasive arguments and convincing tactics, including to ensure these women would go through with their children's immunisation plans and follow this through by bringing their children to the staterun creche (Anganwadi) centre which also provided nutritious food handouts. The work of motivation was itself based on a lot of preparatory 'field-based' work (field ka kaam) which included monthly household surveys (an average of 10 households per day) as part of providing a detailed socioeconomic and maternal health related profile of the village (gaon ki bhumika). As one ASHA put it, 'the whole burden of maternal health work has come to rest on us'. This was an observation made especially in comparison with the work of the ANM, a permanent member of the safe motherhood programme with a salary of 30,000-40,000 rupees (approximately 500-600 USD) a month in 2015 compared with the honorary position of the ASHA. Apart from a small salary of 1600 rupees (approximately 30 USD) per month, women who were recruited as ASHAs would get cash-based incentives linked to their performance (ANM could also access this if they accompanied women to hospital). As Renu, ${ }^{5}$ an ASHA speaking for the rest of the focus group, explained,

Apart from my salary of 1600/- [paid by the Women and Child development department into my bank account online], I receive Rs 300/- online for registration of women and 3 antenatal check-ups. I then get 300/- whenever I accompany a pregnant mother to a government hospital. I also receive 100/- for every child vaccinated against measles and 50/- for a DPT booster administered. If I get a woman to undertake sterilisation after 2 children, I will get 1200/-, other wise 200/- for women who go in for sterilisation after 3 children.

There was an overall sense among the ASHA I talked to of a highly imbalanced and unjust remuneration between ASHA and ANMs as well as a lack of recognition (pehchan) of their work as ASHA compared with the ANM.

Apart from a nominal salary, hierarchised cash incentives (with more money for convincing women of lower birth orders to undertake sterilisation) have contributed to a culture of competitiveness between the ASHA and ANM where each strives to accompany the labouring woman for birth or sterilisation. Renu said each ASHA was in competition with her ANM around the 'targets' they had to fulfil but that they often lost out on being remunerated as the ANM was their superior and supervised their work. The women whom Renu motivated in the village could not be registered by her if they decide to receive immunisation, undergo sterilisation or give birth in hospitals because the ANM says unless they receive care from the ASHA at the

\footnotetext{
${ }^{5}$ All names and other personal identifiers in the chapter have been changed to protect privacy and confidentiality.
} 
primary health sub-centre, they will not be registered as part of the ASHA's quota. This seemed to be an unofficial regulation imposed by the ANM as it was not stated in the policy documents. Renu and other ASHAs that I spoke to suggested that this was a big issue because it caused their performance, and subsequently, their remuneration to be poor. Renu said 'the big madam (supervisor) at Goner asks me what is the reason my target is so low' and 'what can I say to her'? Renu explained to me that the ASHA are set a target of motivating 12-13 pregnant women a month for antenatal care (vaccines and tablets) and hospital delivery. I am surprised by the use of the word 'target' previously used to indicate numbers of women who were motivated to undertake sterilisation in the 1970s when the word gained a negative connotation given the coercion associated with state policy and the evaluation of ANM performance at the time. In March 1998, I had interviewed Sushma, the Malayali ANM who had been posted to work in the regional primary health sub-centre in the Goner area of Jaipur district. She only talked to me about the significance of the family planning work and the targets she was assigned. Sushma specified that her target for 1998 was 53 cases, higher than in the previous year when it had been 35 cases which she had exceeded. When I pointed out that at the central level at the time there was a huge push for expunging family planning targets, she said the only change she had experienced was that 'cases didn't bring in money anymore' (i.e., no cash incentives were attached to this kind of work anymore but they were still expected to meet the sterilisation numbers). In more current ASHA practice, its use indicates how the category 'target' (rephrased as 'Expected Levels of Achievement' or ELA; Iyengar \& Iyengar, 2000) has not only regained a monetary connotation but more so become an overall metric of ASHA performance, proliferating as a technique of reproductive governance.

It was striking to observe, for instance, that the ASHA health workers had a contraceptive bias towards sterilisation similar to others in her community (a fact little recognised in various ASHA training literature). This bias is strongly driven by a pressure to fulfil 'targets' set by the state as Donnelly (2013) has also found in her study in Udaipur district in Rajasthan. In addition, I have suggested that the ASHAs' inclination to reinforce the benefits of sterilisation rather than other forms of reversible methods is also largely because, she herself is convinced of the harmful nature of the copper-T (intrauterine device) and Mala $\mathrm{N}$ (hormonal contraceptive pills) based on her own experiences and observations in her community (most ASHA have undergone sterilisation or use condoms). I was repeatedly told by ASHA about the safety of sterilisation procedures compared to IUD insertions or hormonal pill regimes. Ethnographic insights from 1998 and through 2010 on contraceptive practice in peri-urban Jaipur especially among older Hindu and Muslim women showed recourse to sterilisation among a certain demographic of women (older) who had achieved a desired family size (three to four children with at least one son) (Unnithan-Kumar, 2010). Given the choice, the practice of sterilisation was regarded as safe and favoured above intrauterine devices by this generation of women mainly because it required least intervention and follow-up by health workers. Here we find 
'safety' conceptualised as protection from the inexperience of health workers. It was not so much that fears of sterilisation were not present as indeed the many stories of botched operations confirmed (Sarojini et al., 2015), but rather it was more the case that tubectomies were regarded as the least risky option.

Similarly, users perceived reversible forms of contraception without the back up of appropriate counselling and paramedic support as 'unreliable' (Iyengar \& Iyengar, 2000). These observations reinforce the statistics from the latest demographic survey which show that while $40 \%$ of women do not use any contraceptive method, $8.7 \%, 2.4 \%$ and $1.2 \%$ go in for the condom, pill and intrauterine device, respectively, compared to $41 \%$ of women who use sterilisation (IIPS, 2017). According to my respondents in peri-urban Jaipur district, intrauterine devices get lost in the upper abdomen where they were believed to get 'stuck', hurting their partners during sex (fieldwork conversations with Unnithan, 2019). Contraceptive pills were also less popular as they required both regularity and commitment, difficult to sustain by women who experienced heat and dizziness which they perceived as dangerous side effects. Condoms were regarded as equally problematic and shameful as they involved openly alluding to intercourse and talking about sex between spouses. A combination of ASHA experience and state directives to fulfil targets thus combines to influence their focus on sterilisation promotion practices on-the-ground, in line with the remuneration incentive which they receive for this. A senior NGO worker commenting on the embeddedness of the ASHA within her community values and beliefs suggested to me the misplaced expectation of health planners about the effectiveness of the ASHA, 'when she cannot even contest the authority of her mother-in-law': asha apne saas ka virodh jub nahi kar sakti to kis ghar mein ja ke ladegi? (when the ASHA cannot challenge her own mother-in-law then in which house can she go and fight for change?). Similar observations on the social context in which the ASHA in Rajasthan work have also been made by other scholars (Roalkvam, 2014, Mishra, 2014, for example). Given the difficult social negotiations with powerful members in the community, family and household, the ASHA often also promoted family and indigenous ideas and practices to do with childbearing. In their role in promoting state directives on reproductive health policies, ASHA more so than the ANM who did not belong to the communities she served, was at once an agent of and subject to State policy processes, and of her community's ideologies, preferences and practices related to childbirth and reproductive care. The ASHA were subject to the fulfilment of contraceptive and other 'targets' to do with safe motherhood as stipulated by State policy and programmes. They were also subject to control by ANMs over the process of achieving their targets. Their work promoted contraceptive choice and rights as stipulated by the state but was also constrained in offering 'restricted choice' according to their community experiences which regarded sterilisation as the least risky option for reproductive control. In this sense the ASHA embodies and symbolises conflicted reproductive governance in India. 


\section{Concluding Discussion: Contrariness as Effective Policy}

Indian family planning policies reflect a State entangled within the desire to promote the liberal rights-based values of informed consent, choice and participation on the one hand, and the wish to be guided by economic principles and a demographic rationale based on fertility regulation and population management, on the other hand. The resulting conflicting policies embody what Ram describes as a condition of the State being caught between two distinct guiding principles of liberalism and developmentalism. These principles become manifest in dual processes whereby they are both reiterated by the state and simultaneously subject to erosion (Ram, 2001, p. 85).

Family planning has been a focus throughout Indian health planning and policy since its inception as a postcolonial, modern nation state. However, as I have discussed in this chapter, its policy approach changed, from a focus on compulsory, non-reversible sterilisation to an ostensibly rights-based voluntary approach. This was a result of the Cairo deliberations where Indian feminists and health activists took the state to task for the atrocities committed through a coercive promotion of sterilisation (especially tubectomies), which, they observed, openly denied the human rights of bodily autonomy of its citizens (mainly poor women). Following the 'turn to rights' and the Indian State's pledge to promote informed choice and comprehensive counselling with regard to contraceptive methods, there was a policy swing towards reversible contraceptive methods. Under the National Rural Health Mission (NRHM), in 2005 the Government of India also promoted incentivised institutional birth alongside financially rewarded voluntary family planning programmes. The creation of a new category of health worker, the ASHA to work under instruction of the ANM is emblematic of the state's twin policy. Both workers are required to undertake the dual responsibility of promoting 'safe delivery' as well as 'voluntary' family planning. On the ground, this translates into the delivery of a 'package of services', which promote child immunisation, institutional delivery as well as contraceptive choice.

Ethnographic observations of the work of health workers and a review of the policies from 1998 to 2015 have shown, however, that contraceptive targets have remained a powerful regulator of health-worker practices. Public health workers continue to be bound in terms of their job security to measures of Expected Levels of Achievement (ELA targets; Iyengar \& Iyengar, 2000) in their family planning work. The ELA incorporate the achievement of a certain expected 'target' number of family planning cases (Visaria, 2000). A 'target'-based approach has thus continued to dominate the outlook of health workers even as health provision takes on a new, rights-based form and language (personal communication with CSO directors and policy makers K. Iyengar, A. Das, V. Ramachandran; also see Visaria, 2000; Das \& Uppal, 2012).

Ethnographic work with the ASHA workers discussed in the chapter further suggests that the nuanced, rights-based framing and language of civil society organisations which influenced the $\mathrm{RCH}$ policies has been lost in the processes of 
implementation. With a lack of further translation and connection with the lifeworlds of local health workers, these notions contend with the perceptions that local health workers have of what is expected of them by their communities and the State. There have been similar processes at work in the pre-rights policy era of the 'Women's Development Programme' (WDP) in Rajasthan in the 1980s (Unnithan \& Srivastava, 1997) where the ideas of empowerment instilled by feminist activist groups were challenged by the village-level functionaries whose basis of engagement was to procure permanent employment contracts rather than action rightsbased change. These observations suggest that overtly rights-based policy approaches adopted by the State have not necessarily permeated beyond the programme documents to engage community health workers in the ways imagined within policy-CSO-academic discourse on rights (Unnithan \& Pigg, 2014). As a policy frame, a rights-based approach to family planning may thus be failing as a regulatory technique of reproductive governance as Morgan and Roberts (2012) define it. For a State keen to exercise reproductive control, the pursuit of contrary family planning agendas may be an effective strategy after all.

\section{References}

Anagost, A. (1995). A surfiet of bodies: Population and the rationality of the state in Post Mao China. In F. Ginsburg \& R. Rapp (Eds.), Conceiving the new world order (pp. 22-41). University of California Press.

Arnold, D. (2006). Official attitudes to population, birth control and reproductive health in India, 1921-1946. In S. Hodges (Ed.), Reproductive health in India: History, politics, controversies (New perspectives in South Asian history, No. 13, pp. 22-51). Orient Longman.

Biehl, J. (2004). The activist state: Global pharmaceuticals, AIDS and citizenship in Brazil. Social Text, 80(22), 105-132.

Brunson, J. (2016). Planning families in Nepal: Global and local projects of reproduction. Rutgers University Press.

Brunson, J. (2019). Tool of economic development, metric of global health: Promoting planned families and economized life in Nepal. Social Science \& Medicine, 254(112298). https://doi. org/10.1016/j.socscimed.2019.05.003

Chen, J. (2011). Globalising, reproducing and civilising rural subjects: Population control policy and constructions of rural identity in China. In C. Browner \& C. Sargeant (Eds.), Reproduction, globalisation and the state: New theoretical and ethnographic perspectives. Duke University Press. https://doi.org/10.1215/9780822393948-004

Chhatterjee, N., \& Riley, N. (2001). Planning and Indian modernity: The gendered politics of fertility control. Signs, 26(3), 811-845.

Das, V. (2015). Affliction: Health, disease and poverty. Fordham University Press.

Das, A., \& Uppal, L. (2012). Family planning in India: A need to review our current approaches. Publication of the National Coalition against the Two Child Norm and Coercive Population Policies. [document made available by authors].

De Zordo, S. (2012). Programming the body, planning reproduction, governing life: The '(ir-) rationality' of family planning and the embodiment of social inequalities in Salvador da Bahia (Brazil). Anthropology \& Medicine, 19(2), 207-223. https://doi.org/10.1080/1364847 0.2012 .675049 
Dean, M. (2001). 'Demonic societies': Liberalism, biopolitics and sovereignty. In T. Blom Hanson \& F. Stepputat (Eds.), States of imagination: Ethnographic explorations of the postcolonial state (pp. 41-65). Duke University Press.

Dhanraj, D. 2011 (1991). Something like a war - YouTube. www.youtube.com/ watch? $\mathrm{v}=\mathrm{J} 4 \mathrm{vaELkhjhs}$

Donnelly, K. (2013). Accredited social heath activists' knowledge, attitudes and practices regarding family planning in Southern Rajasthan. ARTH, Udaipur: Draft report.

Foucault, M. 1998 (1976). The history of sexuality: 1. The will to knowledge. Penguin Books.

Ginsburg, F., \& Rapp, R. (1995). Conceiving the new world order: The global politics of reproduction. University of California Press.

GOI, Government of India. (2000). National Population Policy. Ministry of Health and Family Welfare. https://www.nhp.gov.in/national-population-policy-2000_pg. Accessed 10 Oct 2010.

GOI, Government of India. (2007). Document 2: The principles and evidence base for state RCH II Programme Implementation Plans (PIPs). http://www.xiss.ac.in/RCH/Others/RCHII.pdf. Accessed 9 Aug 2014.

GOI, Government of India. National Health Portal, Bhore Committee Report 1946. https://www. nhp.gov.in/bhore-committee-1946_pg. Accessed 11 June 2020.

GOI, Government of India, Ministry of Health and Family Welfare. (2006). National rural health Mission: Draft report of the reconstituted task group on public-private partnership under the NRHM. https://nhm.gov.in/images/pdf/guidelines/nrhm-guidelines/ppp_task_force_report_ draft.pdf. Accessed 5 June 2012.

GOI, Government of India, Ministry of Health and Family Welfare. (n.d.). National rural health mission. http://www.mohfw.nic.in/NRHM/Documents/Mission_Document.pdf. Accessed 11 Nov 2010.

Greenhalgh, S. (1995). Anthropology theorizes reproduction: Integrating practice, politicaleconomic and feminist perspectives. In S. Greenhalgh (Ed.), Situating fertility: Anthropological and demographic enquiry (pp. 1-3). Cambridge University Press.

Greenhalgh, S. (2005). Globalisation and population governance in China. In A. Ong \& S. J. Collier (Eds.), Global assemblages: Technology, politics, and ethics as anthropological problems (pp. 354-372). Blackwell.

Gupta, A. (2001). Governing population: The integrated child development services program in India. In T. Blom Hanson \& F. Stepputat (Eds.), States of imagination: Ethnographic explorations of the postcolonial state (pp. 65-67). Duke University Press.

Hanson, T. B., \& Stepputat, F. (Eds.). (2001). States of imagination: Ethnographic explorations of the postcolonial state. Duke University Press.

Hodges, S. (2006). Reproductive health in India: History, politics, controversies. New perspectives in South Asian history No. 13. Orient Longman.

International Institute for Population Sciences (IIPS) and ICF. (2017). National Family Health Survey (NFHS-4), India, 2015-16: Rajasthan. IIPS. https://dhsprogram.com/what-we-do/survey/survey-display-355.cfm. Accessed 22 July 2020.

Iyengar, K., \& Iyengar, S. (2000). The Copper T 380A IUD: A ten year alternative to female sterilisation. Reproductive Health Matters, 18(16), 125-133. https://doi.org/10.1016/ S0968-8080(00)90194-0

Jeffrey, R., \& Jeffrey, P. (1997). Population, gender and politics: Demographic change in rural India. Cambridge University Press.

Kanaaneh, R. (2002). Birthing the Nation: Strategies of Palestinian Women in Israel. California.

Lane, S. (1994). From population control to reproductive health: An emerging policy agenda. Social Science and Medicine, 39(9), 1303-1304. https://doi.org/10.1016/0277-9536(94)90362-X

Mavalanker, D., Vora, K., \& Sharma, B. (2010). The midwifery role of the auxiliary nurse midwife. In K. Sheikh \& A. George (Eds.), Health providers in India: On the front-lines of change (pp. 38-57). Routledge.

Mishra, A. (2014). 'Trust and teamwork matter': Community healthworkers' experiences in integrated service delivery in India. Global Public Health, 9(8), 960-974. https://doi.org/10.108 $0 / 17441692.2014 .934877$ 
Morgan, L., \& Roberts, E. (2012). Reproductive governance in Latin America. Anthropology \& Medicine, 19(2), 241-254. https://doi.org/10.1080/13648470.2012.675046

Muttreja, P. (2019, November). ICPD@25: India must prioritise reproductive rights. The Hindustan Times.

NHSRC, National Health Systems Resource Centre, GOI. (2011). ASHA programme: ASHA Resource Centre Strengthening. Policy and Guidelines I National Health Systems Resource Centre, MoHFW, Government of India. www.nhsrcindia.org/catgory-detail/ policy-and-guidelines/MTc=

Qadeer, I., \& Viswanathan, N. (2004). How healthy are health and population policies? The Indian experience. In A. Castro \& M. Singer (Eds.), Unhealthy health policies: A critical anthropological examination (pp. 145-163). Altamira Press.

Ram, K. (2001). Rationalising fecund bodies: Family planning policy and the modern Indian nation state. In M. Jolly \& K. Ram (Eds.), Borders of being: Citizenship, fertility and sexuality in Asia and the Pacific. University of Michigan Press.

Ramasubban, R., \& Jejheebhoy, S. (Eds.). (2000). Women's reproductive health in India. Rawat.

Rao, M. (Ed.). (1999). Disinvesting in health: The World Bank's prescriptions for health. Sage.

Roalkvam, S. (2014). Health governance in India: Citizenship as situated practice. Global Public Health, 9(8), 910-926. https://doi.org/10.1080/17441692.2014.941900

Sarojini, N., Sri, S. B., Ambhore, V., \& Venkatachalam, D. (2015). Bilaspur sterilisation deaths: Evidence of oppressive population control policy. Indian Journal of Medical Ethics, 12(1), 2-5.

Senderowicz, L. (2019). 'I was obliged to accept': A qualitative exploration of contraceptive coercion. Social Science and Medicine, 239C, 112531. https://doi.org/10.1016/j. socscimed.2019.112531

Sharma, A., \& Gupta, A. (2006). Introduction: Re-thinking theories of the state in an age of globalisation. In A.Sharma \& A. Gupta (Eds.), The Anthropology of the State: A Reader (pp. 1-43). Blackwell Publishing.

Shore, C., Wright, S., \& Pero, D. J. (Eds.). (2011). Policy worlds: Anthropology and the analysis of contemporary power. Berghahn.

Singer, M., \& Castro, A. (2004). Anthropology and health policy: A critical perspective. In A. Castro \& M. Singer (Eds.), Unhealthy health policies: A critical anthropological examination (pp. xi-xx). Altamira Press.

Storeng, K., \& Béhague, D. (2017). 'Guilty until proven innocent': The contested use of maternal mortality indicators in global health. Critical Public Health, 27(2), 163-176. http://dx.doi. org/10.1080/09581596.2016.1259459

Unnithan, M. (2019). Fertility, health and reproductive politics: Re-imagining rights in India. Routledge. https://doi.org/10.1111/dech.12135

Unnithan, M., \& Heitmeyer, C. (2014). Challenges in 'translating' human rights: Perceptions and practices of civil society actors in Western India. Development and Change, 45(6), 1361-1384.

Unnithan, M., \& Pigg, S. L. (2014). Sexual and reproductive health rights and justice - Tracking the relationship. Culture, Health and Sexuality, 16(9-10), 1181-1245. https://doi.org/10.108 0/13691058.2014.945774

Unnithan, M., \& Srivastava, K. (1997). Gender politics, development and women's agency in Rajasthan. In R. D. Grillo \& R. L. Stirrat (Eds.), Discourses of development (pp. 157-182). Berg.

Unnithan, M., Heitmeyer, C., \& Kachhawa, P. (2010). Thinking through rights-based development in health: Institutional approaches to social inequality and gender violence in reproductive, maternal and sexual health (All India consultation and dissemination workshop report, Institute of Development Studies, Jaipur, April 9th-10th 2010). TTC Centre.

UNFPA. (2004). State of the world population 2004: The Cairo Consensus at ten: Population, reproductive health and the global effort to end poverty. https://www.unfpa.org/sites/default/ files/pub-pdf/swp04_eng.pdf. Accessed 110ct 2021.

UNFPA. (2008). State of the world population: Reaching common ground: Culture, gender and human rights.https://resourcecentre.savethechildren.net/node/1278/pdf/1278.pdf. Accessed 11 Oct 2021. 
Unnithan-Kumar, M. (2010). Female selective abortion beyond 'Culture': Gender inequality and family making in a globalising India. Culture, Health and Sexuality, 12(2),153-166. https://doi. org/10.1080/13691050902825290

Van Hollen, C. (2003). Birth on the threshold: Childbirth and modernity in South India. University of California Press.

Varley, E. (2012). Islamic logics, reproductive rationalities: Family planning in northern Pakistan. Anthropology \& Medicine, 19(2), 189-206. https://doi.org/10.1080/13648470.2012.675044

Visaria, L. (2000). From contraceptive targets to informed choice. In R. Ramasubban \& S. Jejheebhoy (Eds.), Women's reproductive health in India (pp. 331-383). Rawat.

Wright, S. (2011). Studying policies, methods, paradigms, perspectives - Introduction. In C. Shore, S. Wright, \& D. Pero (Eds.), Policy worlds: Anthropology and the analysis of contemporary power (pp. 27-32). Berghahn.

Open Access This chapter is licensed under the terms of the Creative Commons Attribution 4.0 International License (http://creativecommons.org/licenses/by/4.0/), which permits use, sharing, adaptation, distribution and reproduction in any medium or format, as long as you give appropriate credit to the original author(s) and the source, provide a link to the Creative Commons license and indicate if changes were made.

The images or other third party material in this chapter are included in the chapter's Creative Commons license, unless indicated otherwise in a credit line to the material. If material is not included in the chapter's Creative Commons license and your intended use is not permitted by statutory regulation or exceeds the permitted use, you will need to obtain permission directly from the copyright holder.

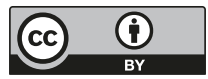

